\title{
INSTRUMENTOS E TÉCNICAS PARA INVESTIGAÇÃO EM ENFERMAGEM PSIQUIĀTRICA. \\ I - CLASSIFICAÇÃO DAS ATIVIDADES EXECUTADAS POR PESSOAL DE ENFERMAGEM PSIQUIÁTRICA
}

Maria Aparecida Minzoni *

MINZONI, M.A. Instrumentos e técnicas para investigação em enfermagem psiquiátrica I - Classificação das atividades executadas por pessoal de enfermagem psiquiátrica. Rev. Esc. Enf. USP, São Paulo, 14 (3): 287-298, 1980.

A autora apresenta um estudo das atividades exercidas pelo pessoal de enfermagem em hospitais psiquidtricos no qual utilizou o método de observação intermitente.

Neste estudo, em que nos propusemos a conhecer que atividades o pessoal de enfermagem, segundo seu nível, estava executando, usamos a técnica de observação intermitente. Para isso, foi necessário construir uma lista de atividades e classificá-las de acordo com as necessidades dos pacientes.

A técnica de observação intermitente consiste na observação, em intervalos regulares, do que o pessoal está fazendo. Essa observação é realizada em cinco dias da semana. Os sábados e domingos são excluídos porque o serviço apresenta-se diferente da rotina dos outros dias. Para um estudo das atividades, nesses dias, deve-se fazer a observação de cinco sábados e cinco domingos consecutivos.

De modo geral, o período de observação é de 15 minutos e num espaço de 24 horas, seguindo-se o esquema dos tumos ou plantōes de enfermagem. Essa técnica foi descrita por ARNSTEIN (1954), porém, há estudiosos que usaram a técnica modificada, seja em relação aos intervalos, seja em relação aos dias da semana, ou turnos de observação (FERREIRA SANTOS \& MINZONI, 1968; BURKE et alii, 1956; STEVENS \& HALPERT, 1957).

Para um estudo desse tipo é necessário, primeiramente, preparar a classificação das atividades (Anexo I), o modelo das folhas para anotação das atividades observadas (Anexos II e II) e as pessoas que atuarão como observadores.

\section{TÉCNICA DE OBSERVAÇÃO}

O pessoal de enfermagem é observado enquanto realiza seu trabalho, nas unida-

- Professor Titular de Enfermagem Psiquiátrica junto ao Departamento de Enfermagem Psiquiátrica e Ciências Humanas da Escola de Enfermagem de Ribeirão Preto - USP. 
des de enfermagem, durante seu plantão, em períodos de 15 minutos, e a seguir faz os registros de acordo com uma lista de atividades, previamente preparada (Anexo I).

Para melhor compreensão da técnica serão definidos os termos utilizados, os passos a serem cumpridos pelos observadores e a forma de registro. Como exemplo do que deve ser feito no preparo desse tipo de trabalho apresentaremos, também, uma classificação do pessoal de enfermagem, segundo seu nível e uma escala de horários.

\subsection{Definiçāo de termos}

Trabalho de enfermagem - Inclui todas as atividades executadas pelo pessoal de enfermagem, as quais foram classificadas em áreas.

Ärea - Refere-se à qualidade e ao tipo de trabalho executado com o paciente, ou para o paciente, e atividades de natureza pessoal. As áreas foram classificadas em sete, a saber: BÁSICAS, DE TRATAMENTO, DE COMUNICAÇĀO, DE INTERRELACIONAMENTO, ADMINISTRATIVA, DOMESTICA E AUSENCIA DA UNIDADE.

BASICAS: Atividades executadas com, ou para o paciente, pelo fato de ele ser uma pessoa com necessidades básicas, como: alimentação, sono, excreção e higiene.

DE TRATAMENTO: Atividades executadas com, ou para o ser humano, pelo fato dele estar doente. Nessa área foram considerados os tratamentos relacionados à terapia somática como eletrochoque, medicação; terapia social, vista apenas nos aspectos de ocupação e recreação; e proteção do paciente como restrição, observação enquanto o paciente dorme.

DE COMUNICAÇAOO: Atividades necessárias ao bom entrosamento da equipe de enfermagem com a equipe de tratamento e demais pessoas do hospital, visando ao bom funcionamento da instituição. Essa área inclui relatórios escritos e orais, ordens médicas e troca de informaçðes sobre o paciente.

DE INTER RELACIONAMENTO: Atividades onde há uma comunicação direta com o paciente (verbal ou não), mas que são independentes do atendimento das necessidades básicas ou dos tratamentos.

ADMINISTRATIVA: Atividades que objetivam o bom funcionamento das unidades de enfermagem, através da execução da rotina hospitalar, supervisão do pessoal de enfermagem e distribuição do serviço.

DOMESTICA: Atividades que existem num hospital, da mesma forma que existe em qualquer habitação. Estão relacionadas à limpeza e ordem, conservação e manutenção do material e do prédio.

AUSENCIAS: Foi registrado como ausente o funcionário que constava da escala do dia e tumo e não era localizado na sua unidade de serviço, dentro do período de observação. Foi feita uma distinção entre estar ausente por necessidade de serviço, por exemplo: ir à lavanderia buscar roupa para o paciente; e estar ausente por motivos particulares, por exemplo: tomar café. 
A classificação das atividades dentro de cada área específica (Anexo I), foi elaborada de acordo com sua execução, tendo em vista a nossa experiência de trabalho com pessoal de enfermagem, em vários hospitais, e os conhecimentos adquiridos através de literatura. Essa divisão é apresentada a seguir, sem os códigos.

As atividades da área BÁSICA compreendem:

Agir pelo paciente - quando o paciente está incapacitado de cuidar de si e precisa que a enfermeira faça tudo por ele. Exemplo: dar banho no paciente.

Ajudar o paciente - quando o paciente pode cuidar de si, mas não consegue fazê-lo sozinho. Exemplo: ajudar o paciente a se vestir, porque está sonolento devido ao tratamento recebido.

Lembrar o paciente - quando o paciente pode cuidar de si, mas não o faz porque se esquece, não se interessa por sua pressoa, ou não tem hábito. Exemplo: quando diz ao paciente que está na sua vez de tomar banho.

Proporcionar meios - quando o paciente só pode agir se lhe são proporcionados os meios para a ação. Exemplo: paciente só pode trocar de roupa se o pessoal de enfermagem lhe fornece a roupa limpa.

\section{Atividades da área de TRATAMENTO:}

Direta - tudo que é realizado junto ao paciente ou na sua pessoa. Exemplo: dar medicação oral, aplicar-lhe inieção.

Indireta - tudo que é feito para o paciente, visando seu cuidado ou bem-estar. Exemplo: preparar medicação, esterilizar material, anotar a medicação dada.

Atividades da área de COMUNICAÇÃO:

Direta - a) quando o pessoal de enfermagem dirige-se diretamente ao médico ou a seu superior imediato. Exemplo: informar ao médico que o doente está se queixando de cefaléia;

b) quando a comunicação entre o pessoal de enfermagem é feita de pessoa para pessoa. Exemplo: informaçðes que são dadas durante a troca de plantão;

c) quando o médico procura o pessoal de enfermagem e conversa com ele sobre o paciente ou sobre o serviço.

Indireta - a) quando as informaçð̃es são transmitidas através de bilhetes, livros de ordem, relatórios escritos;

b) quando o pessoal de enfermagem não conversa diretamente com o médico, ou seu superior imediato, mas dá as informaçðes através de uma terceira pessoa.

\section{Atividades na área de INTER-RELACIONAMENTO:}

Agir com o paciente - quando o pessoal de enfermagem está se relacionando com o paciente através de conversas, gestos ou alguma atividade.

Agir pelo paciente - quando o pessoal de enfermagem relaciona-se com o paciente, executando atividades que visam o seu bem-estar, mas sem a participação do paciente. Exemplo: observar o paciente durante o sono (noturno).

Não agir - quando o pessoal de enfermagem está presente, mas não mantém contato com o paciente, seja por gestos, conversa ou execução de alguma atividade conjunta. É apenas mais uma pessoa no local. 


\section{Atividades da área de ADMINISTRAÇAOO:}

De enfermagem - quando as atividades são da responsabilidade do pessoal de enfermagem.

De não enfermagem - quando as atividades realizadas são da responsabilidade de outros serviços, mas foram feitas pelo pessoal de enfermagem.

\section{As ausências compreendem:}

$A$ serviço: quando o pessoal de enfermagem está ausente da unidade, mas em atividades da responsabilidade da enfermagem. Exemplo: estar acompanhando paciente que foi consultar profissional em outro hospital.

De natureza particular - quando está executando qualquer tipo de atividade para si mesmo, ou para os colegas. Exemplo: tomando café.

\subsection{Passos da observação}

De modo geral, as instruçð̄es dadas aos observadores resumem-se no seguinte:

a) Cada observador deverá observar todo o pessoal de enfermagem existente na unidade, nos horários determinados, dentro do período de plantão. Exemplo: das $7 \mathrm{~h}$ às $7 \mathrm{~h} 15 \mathrm{~m}$; das $7 \mathrm{~h} 15 \mathrm{~m}$ às $7 \mathrm{~h} 30 \mathrm{~m}$; das $11 \mathrm{~h} 45 \mathrm{~m}$ às $12 \mathrm{~h}$, etc., até completar o período de plantão;

b) as observaçð̃es deverão ser feitas dentro de períodos de 15 minutos;

c) em cada período de 15 minutos a observaçáo deverá ser iniciada em pontos diferentes da unidade;

d) o observador deverá anotar o que as pessoas estão fazendo, à medida em que as for encontrando;

e) percorrida toda a unidade, deverá procurar saber se todos os funcionários foram encontrados. Se dentro desses 15 minutos algum não for localizado, será considerado ausente;

f) terminado o período de 15 minutos, iniciar-se-á nova observação completa. Cada funcionário é anotado uma só vez, dentro de cada período de 15 minutos;

g) se um funcionário estiver ausente durante um ou mais períodos, o observador, quando o localizar novamente, deverá perguntar-lhe onde esteve e registrar;

h) observar, sem interferir no trabalho que observa; anotar a ação, no momento em que está sendo realizada pelo funcionário;

i) quando o observador tiver dúvidas sobre o que estiver sendo feito, perguntará à pessoa observada;

j) não trabalhar com o paciente;

h) cada observador não deverá ter mais de 10 pessoas para observar.

\subsection{Registro das observações}

Para o registro das observações usa-se uma ficha especial (Anexo II e III). Esta ficha é constituída de cabeçalho, quatro colunas (A, B, C e D), códigos e siglas no rodapé. O cabeçalho permite identificar o observador, locak, dia, hora e turno da observação e a numeração da folha.

\section{Anotam-se nas colunas:}

A - A hora correspondente aos períodos de 15 minutos;

B - A categoria da pessoa observada, de acordo com as siglas. A pessoa é identificada com uma letra, que corresponde ao seu nome, para que náa seja observada mais de uma vez no mesmo período;

C - Os códigos correspondentes a cada atividade. No rodapé existe um resumo 
dessas atividades com seu código (Anexo II) e no modelo de lista organizada para esse fim (Anexo I), encontra-se a relação completa;

- a descrição suscinta do que o observador está vendo ser executado.

\subsection{Pessoal de enfermagem, segundo seu nivel}

Nesta apresentação, o pessoal de enfermagem está classificado em três níveis: auxiliar de enfermagem, atendente-chefe e atendente, pois eram as situações encontradas, pela autora, em suas pesquisas.

Auxiliar de Enfermagem - É portador de certificado de Auxiliar de Enfermagem conferido por escola ou curso reconhecido, nos termos da lei (Portaria 106, do Conselho Federal de Educação, de 28 de abril de 1965, que regulamenta o ensino de Auxiliar de Enfermagem pelo sistema federal de ensino, Diário Oficial da União, 10 de maio de 1965).

Atendente - E uma categoria de pessoal de quem se exige apenas que saiba ler e escrever e que pode ter recebido, ou não, treinamento em serviço ou em curso não reconhecido.

Atendente-chefe - É o atendente responsável pelo serviço de enfermagem.

\subsection{Escala de horários}

As fichas de anotação das observaçðes (Anexo I) são preparadas com antecedência. Primeiramente, verifica-se a quantidade necessária para cada turno, contando-se o pessoal de enfermagem existente, diariamente, nas unidades. Para efeitos de observação, considera-se um horário fixo para os tumos. Por exemplo: 1 o turno: das $6 \mathrm{~h}$ as $14 \mathrm{~h}$; 2 ? turno: das $14 \mathrm{~h}$ às $22 \mathrm{~h}$ e 30 turno: das $22 \mathrm{~h}$ às $6 \mathrm{~h}$.

MINZONI, M.A. Tool and procedures for research in psychiatric nursing. I - Classification of the activities performed by nursing personnel. Rev. Esc. Enf. USP, São Paulo, 14 (3): 287-298, 1980.

This is a study of the activities of nursing personnel in psychiatric hospitals, in which the observation method was employed.

\section{REFERENCIAS BIBLIOGRÁFICAS}

ARNSTEIN, M.G. How study nursing activities in patient unit. Washington, Department of health, education and welfare, 1954. (Publication, 370).

BURK, C.; CHALL, C.L; ABDELLAH. F.G. A time study of nursing activities in a psychiatric hospital. Nurs. Res, New York, 5 (1): 27-35, June 1956.

FERREIRA SANTOS, C.A. \& MINZONI. M.A. Estudo das atividades de enfermagem em quatro unidades de um hospital governamental. Rev. Bras. Enf., Rio de Janeiro, $2 I$ (5): 396-442, 1968.

MINZONI, M.A. Assistência de enfermagem psiquiátrica: estudo da situação num município paulista. Ribeirão Preto, 1971. (Tese de doutoramento - Escola de Enfermagem de Ribeirão Preto - USP). p. 69-88.

STEVENS, P. \& HALPERT, P. The nurse's thursday in a psychiatric ward. Nurs. Res, New York, 6 (1): 29-34. 1957. 


\section{A N EXOI}

\section{MODELO DE CLASSIFICAÇÃO DAS ATIVIDADES EXECUTADAS PELO PESSOAL DE ENFERMAGEM}

1. BÄSICAS - As atividades dessa área estão classificadas em:

1.1.1 - Agir pelo paciente - quando o paciente está incapacitado de cuidar de si mesmo e precisa que a enfermagem faça tudo por ele. Exemplo: dar banho no paciente.

1.1.2 - Ajudar o paciente - quando o paciente pode se cuidar, mas não consegue fazé-lo sozinho. Exemplo: ajudar o paciente a se vestir, porque ele está sonolento devido ao tratamento recebido.

1.1.3 - Lembrar o paciente - quando o paciente pode se cuidar sozinho, mas não o faz porque se "esquece", não se interessa por sua pessoa, ou não tem hábito. Exemplo: dizer ao paciente que está na sua vez de tomar banho.

1.2.1 - Proporcionar-lhe meios - quando o paciente só pode fazê-lo se lhe são proporcionados os meios para a ação. Exemplo: paciente só pode trocar de roupa se o pessoal de enfermagem trouxer a roupa limpa da rouparia.

ÁREA BÁSICA

\begin{tabular}{|c|c|c|c|c|}
\hline \multirow[b]{2}{*}{$A T I V I D A D E S$} & \multicolumn{4}{|c|}{ CODIGO } \\
\hline & Agir pelo & Ajudar & Lembrar & $\begin{array}{l}\text { Proporcionar } \\
\text { meios }\end{array}$ \\
\hline $\begin{array}{l}\text { Relacionadas d higiene } \\
\text { Banho, lavar os cabelos, cortar as unhas } \\
\text { lavar as mãos e rosto, escovar os dentes, } \\
\text { vest ir roupa, tirar roupa, trocar roupa. }\end{array}$ & 1.1 .1 & 1.1 .2 & 1.1 .3 & 1.2 .1 \\
\hline $\begin{array}{l}\text { Relacionadas d alimentação } \\
\text { Dar comida na boca do paciente. } \\
\text { Ajudar o paciente a se alimentar. Arru- } \\
\text { mar o prato para o paciente (por comi- } \\
\text { da). Distribuir os alimentos para os aca- } \\
\text { mados ou aqueles que não freqüentam o } \\
\text { refeitório. Dar água ao paciente: na boca, } \\
\text { na mão ou na mesa. Levaro paciente para } \\
\text { o refeitório. }\end{array}$ & 1.1 .1 & 1.1 .2 & 1.1 .3 & 1.2 .1 \\
\hline $\begin{array}{l}\text { Relacionadas ao sono } \\
\text { Preparar a cama. Vestir o paciente. } \\
\text { Levar o paciente para o quarto. Proteger } \\
\text { a cama. Deitar o paciente. }\end{array}$ & 1.1 .1 & 1.1 .2 & 1.1 .2 & 1.2 .1 \\
\hline $\begin{array}{l}\text { Relacionadas d excreçōo } \\
\text { Levar o paciente ao banheiro. Ajudar o } \\
\text { paciente a utilizar-se do banheiro. Indi- } \\
\text { car-lhe o banheiro. Dar a comadre ou } \\
\text { papagaio ao paciente. }\end{array}$ & 1.1 .1 & 1.1 .2 & 1.1 .3 & 1.2 .1 \\
\hline $\begin{array}{l}\text { Relacionadas ao conforto do paciente } \\
\text { Distribuir cigarros. Acender cigarro. } \\
\text { Mudar de cama ou de quarto. }\end{array}$ & 1.1 .1 & 1.1 .2 & 1.1 .3 & 1.2 .1 \\
\hline
\end{tabular}


2. TRATAMENTO - As atividades dessa áre a estão classificadas em:

2.1 - Diretas - tudo que é realizado junto ao paciente ou na sua pessoa. Exemplo: dar medicaçã̃o oral, aplicar a injeção.

2.2 - Indiretas - tudo que é feito para o paciente, visando seu cuidado ou bem-estar. Exemplo: preparar a medicação, esterelizar o material, anotar a medicação dada.

ÁREA DE TRATAMENTO

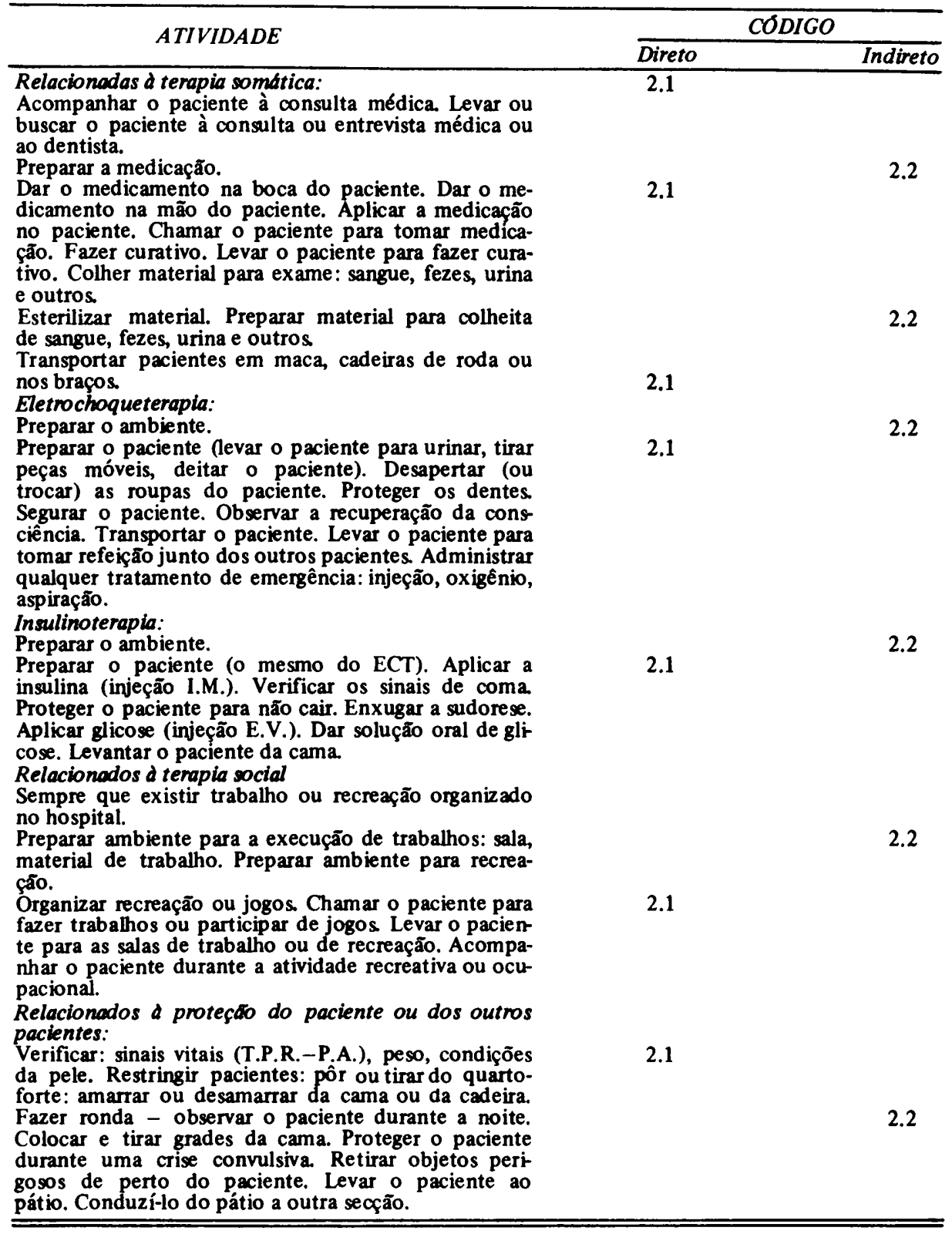


3. COMUNICAÇÃO - Essas atividades estão classificadas em:

3.1 - Direta - a) quando o pessoal de enfermagem se dirige diretamente ao seu superior imediato ou ao médico. Exemplo: informar ao médico que o doente está se queixando de cafeléia;

b) quando a comunicação entre o pessoal de enfermagem é feita de pessoa a pessoa. Exemplo: informaçð̃es que são dadas durante a troca de plantão;

c) quando o médico procura o pessoal de enfermagem e conversa com eles (ou com ele) sobre o paciente ou o serviço.

3.2 - Indireta - a) quando as informaçð̃es são transmitidas através de bilhetes, livros de ordem, relatórios escritos;

b) quando o pessoal de enfermagem não se comunica diretamente com seu superior imediato ou com o médico, mas dá as informaçð̃es através de uma terceira pessoa que serve de intermediário.

ÁREA DE COMUNICAÇÃo

\begin{tabular}{|c|c|c|}
\hline \multirow{2}{*}{ ATIVIDADES } & \multicolumn{2}{|c|}{$C O D I G O$} \\
\hline & Direto & Indireto \\
\hline $\begin{array}{l}\text { Relacionadas d comunicação oral e escrita: } \\
\text { da enfermeira com o pessoal médico em relação ao } \\
\text { paciente. Da enfermeira com o pessoal administrativo, } \\
\text { em relação ao paciente. Da enfermeira com colegas, } \\
\text { em relação ao paciente. } \\
\text { Fazer anotaçoes no relatório de enfermagem. Escrever } \\
\text { ou receber billhetes ou ordens escritas. }\end{array}$ & & 3.2 \\
\hline $\begin{array}{l}\text { Telefonar para o médico. } \\
\text { Ler escala de serviço ou de plantão. } \\
\text { Passar plantão. Receber plantão. }\end{array}$ & $\begin{array}{l}3.1 \\
3.1\end{array}$ & 3.2 \\
\hline
\end{tabular}

4. INTER-RELACIONAMENTO - As atividades dessa área estão classificadas em:

4.1 - Agir com o paciente - quando o pessoal de enfermagem relaciona-se com o paciente através de conversas, de gestos ou alguma atividade.

4.2 - Agir pelo paciente - quando o pessoal de enfermagem relaciona-se com o paciente executando atividades que visam seu bem-estar; mas sem a participação do paciente. Exemplo: observar o paciente enquanto dorme (noturno).

4.0 - Não agir - quando o pessoal de enfermagem está presente, mas não se comunica com o paciente nem por gestos, nem conversando, nem executando alguma atividade junto. É apenas mais uma pessoa no local. 


\begin{tabular}{|c|c|c|c|}
\hline \multirow{2}{*}{ ATIVIDADES } & \multicolumn{3}{|c|}{ CODIGO } \\
\hline & Agir com & Agir pelo & Não agir \\
\hline $\begin{array}{l}\text { Perguntar (entrevista). } \\
\text { Olhar simplesmente. } \\
\text { Trabalhar com o paciente. Conversar. } \\
\text { Receber o paciente (admissão). Preparar o } \\
\text { paciente para sair (alta). Restringir o pacien- } \\
\text { te: quarto-forte; amarrar na cama ou na } \\
\text { cadeira (por castigo). Sair à rua com o pa- } \\
\text { ciente para passear ou fazer compras. } \\
\text { Observar o paciente no pátio. } \\
\text { Sentar ou conversar com os colegas enquan- } \\
\text { to observa os pacientes (noturno). Procurar } \\
\text { pelo paciente, ao verificar se todos estão } \\
\text { presentes. } \\
\text { Separar pacientes em briga. }\end{array}$ & $\begin{array}{l}4.1 \\
4.1\end{array}$ & 4.2 & 4.0 \\
\hline
\end{tabular}

\section{ADMINISTRATIVA - Estão classificadas em:}

5.2 - De enfermagem - quando as atividades são da responsabilidade do pessoal de enfermagem.

5.0 - De não enfermagem - quando as atividades realizadas são da responsabilidade de outros serviços, mas foram feitas pelo pessoal de enfermagem.

\section{ÄREA ADMINISTRATIVA}

\begin{tabular}{|c|c|c|}
\hline \multirow[b]{2}{*}{ ATIVIDADES } & \multicolumn{2}{|c|}{ CODIGO } \\
\hline & $\begin{array}{c}\text { De } \\
\text { Enfermagem }\end{array}$ & $\begin{array}{c}\text { De nōo } \\
\text { Enfermagem }\end{array}$ \\
\hline $\begin{array}{l}\text { Supervisionar funcionários em relação com a execução } \\
\text { do trabalho e disciplina de serviço. Fazer escala e } \\
\text { distribuir o servico. Verificar a falta de material } \\
\text { (roupa, medicamentos, material para execução de } \\
\text { enfermagem). Planejar reuniōes de pessoal de enfer- } \\
\text { magem. Verificar limpeza e ordem na unidade. Esco- } \\
\text { lher paciente para ajudar a fazer algum serviço: cozi } \\
\text { nha, lavanderia, limpeza, etc. Riscar as papeletas e } \\
\text { trocar os papéis preenchidos por limpos. Controlar } \\
\text { os psicotropicos. Preencher o cartão de medicamen- } \\
\text { to. Visitar as enfermarias e os pátios. }\end{array}$ & 5.2 & \\
\hline $\begin{array}{l}\text { Pedir e levar chaves. Abrir e fechar portas. Consertar } \\
\text { fechaduras, torneiras, portas. Contar medicafão nâo } \\
\text { psiquiátrica que os pacientes particulares tomam a } \\
\text { ser paga ao hospital. } \\
\text { Contar o número de pacientes que tomaram eletro- } \\
\text { choque, e os pacientes que foram ao barbeiro para } \\
\text { fim de cobrança pelo hospital. Telefonar para saber } \\
\text { noticia de outras pessoas, em outros hospitais. }\end{array}$ & & 5.0 \\
\hline
\end{tabular}


Limpeza do chão: varrer, encerar, passar pano molha6.2 do, lustrar. Arrumação de cama: arrumar, trocar a roupa, pôr em ordem. Limpeza de banheiro: lavar, varrer, colocar papel, enxugar, encerar. Limpeza de material e empacotamento: vidros, seringas, canecas, etc. Ajuntar a roupa suja e distribuir a limpa. Arrumação de refeitório: arrumar mesa para refeição, tirar a mesa.

\section{AUSENCIAS - Estão classificadas em:}

0.1 - A serviço - quando o pessoal de enfermagem está ausente da unidade, mas em atividades da responsabilidade da enfermagem. Exemplo: estar acompanhando paciente que foi se consultar em outro hospital.

0.2 - De natureza particular - quando está executando qualquer atividade para si mesmo, ou para os colegas. Exemplo: tomando café.

ÁREA DE AUSENCIAS

\begin{tabular}{lcc}
\hline \multicolumn{1}{c}{ ATIVIDADES } & \multicolumn{1}{c}{ CODIGO } \\
\cline { 2 - 3 } & $\begin{array}{c}\text { A } \\
\text { Serviço }\end{array}$ & $\begin{array}{c}\text { De Natureza } \\
\text { Particular }\end{array}$ \\
\hline $\begin{array}{l}\text { Tomar café. Tratar de assuntos particulares. Fazer uso } \\
\text { do banheiro. Limpar sapatos ou outra peça do vestiá- } \\
\text { rio. Telefonar em caráter particular. Dormir durante o } \\
\text { plantão. Fumar no corredor. }\end{array}$ & & 0.2 \\
Buscar roupa limpa na lavanderia. Levar roupa suja. \\
Levar paciente para consulta fora do hospital. Buscar \\
medicamentos na farmácia. Buscar alimentação na \\
cozinha. Estar no consultório médico fora da unidade \\
de enfermagem.
\end{tabular}




\section{FOLHA DE ANOTAÇÃO DAS ATIVIDADES OBSERVADAS}

NOME DO OBSERVADOR

LOCAL.$\ldots \ldots \ldots \ldots \ldots$. DATA $\ldots \ldots \ldots$ HORA . . . . TURNO:.

FOLHA No

\begin{tabular}{cccc}
\hline A & B & C & D - ATIVIDADE \\
Hora & $\begin{array}{c}\text { Pessoal } \\
\text { Observado }\end{array}$ & Área & Descrição do que está sendo feito \\
\hline
\end{tabular}

\section{Á R E A}

1. BASICAS

agtr pelo paciente. . . . . . . 1.1.1

ajuda. . . . . . . . . .

lembrar. . . . . . . . . . . .

proporcionar meios. . . . .

2. TRATAMENTO

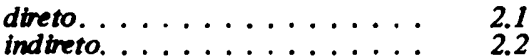

3. COMUNICAÇAOO

direta. ............ 3.1

indireta.
4. INTER-RELACIONAMENTO

agti pelo paciente . . . . . . . 4.2

agtr com o paciente. . ....... 4.1

nổ agt. .......... 4.0

5. ADMINISTRATIVA

de enfermagem ........ 5.2

de nos enfermagem. . . . . . . 5.0

6. DOMESTICA . . . . . . . . 6.2

3.1 O. AUSENCIA

$3.2 \quad$ a servico . . . . . . . . . 0.1

de natureza particular ........... 0.2

Siglas utilizadas para indicar o pessoal observado:

$A E$ - Auxiliar de enfermagem

AT-Chefe - Atendente-chefe
$A T$ - Atendente 
NOME DO OBSERVADOR: . . . Neide .

LOCAL: . . Hospital I . . . . . . DATA: . 20.03.70 . . HORA:. 22̣ . . TURNO. 3??. .. FOLHA № $\ldots . .01 \ldots \ldots \ldots$

\begin{tabular}{|c|c|c|c|}
\hline $\begin{array}{c}\text { A } \\
\text { Hora }\end{array}$ & $\begin{array}{c}\text { B } \\
\text { Pessoal } \\
\text { observado }\end{array}$ & $\begin{array}{l}\text { C } \\
\text { Área }\end{array}$ & $\begin{array}{c}\text { D - ATIVIDADE } \\
\text { Descrição do que está sendo feito }\end{array}$ \\
\hline \multirow[t]{4}{*}{$22 \mathrm{~h} 15 \mathrm{~m}$} & $\mathrm{AT}-\mathrm{E}$ & 2.2 & Preparando medicação \\
\hline & $\mathrm{AT}-\mathrm{G}$ & 1.2 .1 & Distribuindo leite para os pacientes \\
\hline & AT-D & 5.2 & Procurando papeleta do paciente \\
\hline & AT $-\mathbf{W}$ & 3.1 & Conversando com o médico sobre o pacient \\
\hline \multirow[t]{4}{*}{$22 \mathrm{~h} 30 \mathrm{~m}$} & AT-D & 3.2 & Fazendo anotaçð̃es na papeleta \\
\hline & AT-E & 6.2 & Empacotando seringas \\
\hline & AT-W & 2.1 & Aplicando injeção no paciente \\
\hline & AT-G & 2.2 & Preparando medicação para um paciente \\
\hline
\end{tabular}

\section{$\bar{A} \mathbf{R}$ E A}

1. BASICAS

agir pelo paciente. . ......... ajudar. . . . . . . . . . . lembrar. . . . . . . . . . proporcionar meios.

1.1 .1

1.1.2

1.1 .3

1.2.1

2. TRATAMENTO

direto. ............ 2.1

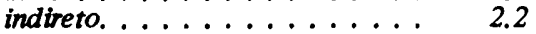

3. COMUNICAÇAO

direta. ...........

indireta. . . . . . . . .
4. INTER-RELACIONAMENTO

agir pelo paciente. . . . . . 4.2

agir com o paciente. ....... 4.1

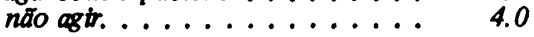

5. ADMINISTRATIVA

de enfermagem ........ 5.2

de näo enfermagem. ...... 5.0

6. DOMESTICA . . . . . . . 6.2

3.1 0. AUSENCIA

$3.2 \quad$ a servico . . . . . . . . . . 0.1

de natureza particular ...... 0.2

Siglas utllizadas para indicar o pessoal observado:

$A E=$ Auxiliar de enfermagem

$A T=$ Atendente

$A T$-Chefe $=$ Atendente-chefe 